\title{
endocrinology
}

Abe, T. 230

Angelopoulos, N.G. 249

Auriemma, R.S. 211

Boikos, S.A. 189

Cattini, P.A. 145

Colao, A. 211

Culler, M.D. 258

Detillieux, K.A. 145

Dufour, H. 258

Ezzat, S. 139

Farneti, G. 240

Faustini Fustini, M. 240

Frank, G. 240
Galdiero, M. 211

Grasso, V. 240

Guillemin, R. 136

Guillen, S. 258

Gunz, G. 258

Holly, J. 154

Horvath, E. 161

Jaquet, P. 258

Jenkins, P.J. 218

Jin, Y. 145

Kaltsas, D. 249

Kaltzidou, V. 249

Katounda, E. 249
Knutzen, R. 139

Kontogeorgos, G. 135, 179

Kopchick, J.J. 264

Kovacs, K. 161

Lombardi, G. 211

Lüdecke, D.K. 230

Lytras, A. 166, 249

Mazzatenta, D. 240

Monson, J.P. 269

Muhr, C. 205

Pasquini, E. 240

Perks, C. 154

Pivonello, R. 211
Protonotariou, A. 249

Rombopoulos, G. 249

Saveanu, A. 258

Sciarretta, V. 240

Stratakis, C.A. 189

Tolis, G. 135, 166, 249

Tsagarakis, S. 135

Tzanela, M. 200

van der Lely, A.J. 264

Webb, S.M. 224

Yang, X. 145

\section{Subject Index Vol. 83, No. 3-4, 2006}

Acromegaly 136, 139, 161, 189, 205, 211, 218, 224, 230, 249, 269

AcroQol questionnaire 224

Active acromegaly 200

Adrenal hyperplasia 189

Apoptosis 179

Arthropathy 249

BIM-23A760 258

BIM-23A779 258

BIM-23A781 258

Breast cancer 218

Cabergoline 258

Cardiovascular diseases 211

Carney complex 166, 189

Chromatin 145

Colorectal cancer 218

${ }^{11} \mathrm{C}$-methionine 205

Cushing syndrome 189

Deprenyl 205

Diabetes 249

Dopamine $\mathrm{D}_{2}$ receptors 205

Endoscopy 240

${ }^{18}$ F-fluorodeoxyglucose 205

Germline mutations 166

Growth hormone 136, 145, 154, $161,211,224,230,269$

- $\quad$ receptor 264
- $\quad$ /insulin-like growth factor-I axis 218

- hormone-secreting tumors 166

Health care costs 139

Health-related quality of life 224

Hereditary pituitary tumors 166

Histones 145

Human pituitary tumors 258

Hypertension 249

Hypogonadism 249

Insulin-like growth factor binding proteins 154

- $\quad$ - I 211

- - factor-I 154, 200, 224, 230

Intracranial tumor 205

Invasive adenomas 230

Isolated familial somatotropinomas 166

Ki-67 179

Locus central region 145

Menin 166

Microsurgery 230

Molecular cytogenetics 179

Multiple endocrine neoplasia type 1 166

- $\quad$ neoplasias 189

Octreotide 258

Oral glucose tolerance test 200 p53 protein 179

Pegvisomant 264

Pituitary adenoma 205, 230

- adenomas 139, 240

- gland 136

- neoplasm 161

- radiotherapy 269

- tumors 189

Pituitary-specific factor Pit-1 145

Positron emission tomography 205

Prostate cancer 218

Sleep apnea 249

SOM-230 258

Somatostatin analog 264

- analogs 249

- receptors 179

Somatotrope adenoma 200

Tissue-specific gene expression 145

Transnasal surgery 230

Transsphenoidal adenectomy 230

- approach 240

Tumor suppressor gene 166

\section{KARGER}

๑ 2006 S. Karger AG, Basel 